\title{
Persistence of Depressive Symptoms in Adolescents
}

\author{
Christi A. Patten, Ph.D., Won S. Choi, Ph.D., Kristin S. Vickers, Ph.D., and John P. Pierce, Ph.D.
}

To examine factors related to the persistence of depressive symptoms, we used a longitudinal follow-up survey of 1,176 adolescents aged 12 to18 in the United States who reported notable depressive symptoms at baseline. Adolescents were interviewed by telephone at baseline in 1989 and at follow-up in 1993. The outcome of interest was a self-report measure of depressive symptoms experienced within the past 12 months at follow-up. Overall, $38.5 \%$ of adolescents reported persistent depressive symptoms. Marked gender differences were found, with $44.5 \%$ of girls reporting notable depressive symptoms at follow-up compared with $28.2 \%$ for boys.

Moreover, current established smokers or experimenters were significantly more likely to report notable depressive symptoms compared with never smokers $(42.2 \%, 41.4 \%$ and $33.6 \%$, respectively). Significant multivariate predictors of notable depressive symptoms at follow-up were female gender, change in sleep problems from 1989 to 1993, change in cigarette smoking status from 1989 to 1993, engaging in physical fights, and lack of participation in sports. Many adolescents report continued depressive symptoms over a period spanning four years. Several predictors of persistent depression were identified that could be important components of interventions targeting depressed adolescents.

[Neuropsychopharmacology 25:S89-S91, 2001]

(C) 2001 American College of Neuropsycho-pharmacology. Published by Elsevier Science Inc.
KEY WORDS: Depression; Adolescence; Cigarette smoking; Sleep; Gender

Adolescent depression has been a focus of recent attention (Cole et al. 1999; Goodman and Capitman 2000). Depressive symptoms during adolescence are associated with a number of adverse health consequences including suicide and future risk of major depressive disorder (MDD) (Frost et al. 1999). Recent longitudinal, population-based studies have examined predictors of development of depressive symptoms in adolescents. In a previous study, we found that gender and cigarette smoking were associated with the onset of depressive symptoms (Choi et al. 1997). In contrast to research ex-

From the Nicotine Research Center and Department of Psychiatry and Psychology, Mayo Clinic, Rochester, MN (CAP, KSV), University of Kansas Medical Center, Kansas City, KS(WSC) University of California, San Diego, CA (JPP).

Address correspondence to: Christi A. Patten, Ph.D., Mayo Clinic, Nicotine Research Center, Colonial 3, 200 First Street SW, Rochester, MN, 55905. Tel.: 507-266-1644, Fax: 507-266-7900, E-mail: patten. christi@mayo.edu amining the course of MDD (Goodyer et al. 1991), there are few epidemiological data on the persistence of depressive symptoms during adolescence. The factors that promote development of depressive symptoms may differ from those that contribute to persistence or remission of depression. An improved understanding of the persistence of depressive symptoms as well as the potentially modifiable correlates of depression is needed to develop more effective intervention programs for depressed adolescents.

In this study, we examine factors associated with persistence of depressive symptoms in a longitudinal sample of 1,176 United States adolescents.

\section{METHODS}

Data were gathered from the 1989 National Teenage Attitudes and Practices Survey (TAPS I) (Allen et al. 1992). TAPS I succeeded in interviewing 9,965 adolescents aged 12-18 years. Only 9,135 respondents reached by 
Table 1. Demographic Characteristics of Persistent Depression, Among Adolescents With Notable Depressive Symptoms at Baseline $(\mathrm{N}=1,176)$

\begin{tabular}{lcc}
\hline Demographics in 1989 & N & $\begin{array}{c}\text { \% with Persistent } \\
\text { Depression in 1993 }\end{array}$ \\
\hline Total & 1,176 & 38.5 \\
Gender & 433 & 28.2 \\
$\quad$ Male & 743 & 44.5 \\
Female & & \\
Age Group & 255 & 34.1 \\
12-13 & 321 & 37.7 \\
14-15 & 600 & 40.8 \\
16-18 & & \\
Race/Ethnicity & 848 & 38.2 \\
$\quad$ White & 188 & 40.4 \\
Black & 92 & 34.8 \\
Hispanic & 48 & 43.8 \\
$\quad$ Asian/other & & \\
School Performance & 151 & 35.8 \\
$\quad$ Much better than avg. & 332 & 36.4 \\
$\quad$ Better than avg. & 693 & 40.1 \\
$\quad$ Average/below avg. & & 42.2 \\
Smoking Status & 282 & 41.4 \\
$\quad$ Current & & 33.6 \\
$\quad$ Experimenter & 435 & \\
$\quad$ Never & 459 & \\
\hline
\end{tabular}

telephone were eligible for follow-up survey in 1993. The follow-up telephone survey (TAPS II) was completed in 1993 by $87 \%$ of these adolescents $(n=7,960)$ who by that time were aged 15-22 years. The National Health Interview Survey (NHIS) uses a multistage sample design to provide national estimates of the non-institutionalized population. All data were weighted according to probability of selection and to represent the United States adolescent population with respect to gender, age, and race/ethnicity. This paper focuses on the 1,176 longitudinal-sample adolescents who reported notable depressive symptoms at baseline.

The measures are described in detail in another report (Patten et al. 2000). Demographic and psychosocial predictors assessed in 1989 included age, gender, race/ ethnicity, cigarette smoking status, and sleep problems. A 5-item modified version of a previously validated scale (Kandel \& Davies 1982) was used to assess depressive symptoms in 1989 and 1993 . Total scores can range from 15 to 30 , and scores of $\geqslant 21$ indicate notable depressive symptoms.

\section{RESULTS}

Table 1 presents the baseline distribution of adolescents reporting notable depressive symptoms in 1993 among the 1,176 reporting notable depressive symptoms in 1989. Of these 1,176 adolescents (433 girls, 743 boys), $453(38.5 \%)$ reported notable depressive symptoms at follow-up. Using multiple logistic regression, signifi-
Table 2. Multivariate Predictors of Persistent Depressive Symptoms

\begin{tabular}{|c|c|c|}
\hline Predictors & $\mathbf{n}$ & $\begin{array}{c}\text { Persistence of } \\
\text { Depressive Symptoms } \\
\text { Odds Ratio }(95 \% \mathrm{CI})^{*}\end{array}$ \\
\hline \multicolumn{3}{|l|}{ Age Group } \\
\hline $12-13$ & 255 & 1.00 \\
\hline $14-15$ & 321 & 1.13 (0.77-1.65) \\
\hline $16-18$ & 600 & $1.15(0.81-1.64)$ \\
\hline \multicolumn{3}{|l|}{ Gender } \\
\hline Males & 433 & 1.00 \\
\hline Females & 743 & $2.21(1.66-2.94)$ \\
\hline \multicolumn{3}{|l|}{ Race/Ethnicity } \\
\hline White & 848 & 1.00 \\
\hline Black & 188 & $1.23(0.85-1.77)$ \\
\hline Hispanic & 92 & $0.81(0.50-1.32)$ \\
\hline Asian/Other & 48 & $1.16(0.61-2.24)$ \\
\hline \multicolumn{3}{|l|}{ Perceived School Performance } \\
\hline Much better than avg. & 151 & 1.00 \\
\hline Better than average & 332 & $0.86(0.56-1.32)$ \\
\hline Average/below average & 693 & $0.94(0.63-1.39)$ \\
\hline \multicolumn{3}{|l|}{ Risky behavior } \\
\hline No & 494 & 1.00 \\
\hline Yes & 682 & $1.11(0.85-1.45)$ \\
\hline \multicolumn{3}{|l|}{ Physical Fights } \\
\hline No & 794 & 1.00 \\
\hline Yes & 382 & $1.38(1.03-1.84)$ \\
\hline \multicolumn{3}{|l|}{ Participation in Sports } \\
\hline No & 519 & 1.00 \\
\hline Yes & 657 & $0.68(0.52-0.89)$ \\
\hline \multicolumn{3}{|l|}{ Smoking Status } \\
\hline Not current established & 799 & 1.00 \\
\hline No in 1989, Yes 1993 & 198 & $1.55(1.09-2.20)$ \\
\hline Yes in 1989, No in 1993 & 24 & $0.68(0.26-1.74)$ \\
\hline Yes in 1989, Yes in 1993 & 155 & $1.25(0.83-1.89)$ \\
\hline \multicolumn{3}{|l|}{ Sleep Problems } \\
\hline No sleep problems & 586 & 1.00 \\
\hline No in 1989, Yes in 1993 & 128 & $3.91(2.57-5.94)$ \\
\hline Yes in 1989, No in 1993 & 312 & $0.77(0.56-1.06)$ \\
\hline Yes in 1989, Yes in 1993 & 150 & $4.15(2.79-6.17)$ \\
\hline
\end{tabular}

${ }^{*} \mathrm{~N}=1,176$. Adjusted odds ratios and $95 \%$ confidence intervals.

cant predictors of notable depressive symptoms in 1993 among those with notable depressive symptoms in 1989 were female gender, engaging in physical fights, and lack of participation in sports (Table 2). As shown in Figure 1, changes in sleep problems and cigarette smoking status from 1989 to 1993 were also predictive.

\section{DISCUSSION}

This study adds to the knowledge on persistence of depressive symptoms from an epidemiological sample of United States adolescents. The study of the trajectory of depressive symptoms and predictors of persistent depression are important components of a developmental psychopathology perspective of adolescent depression (Cole et al. 1999). Nearly 40\% of adolescents reported continued depressive symptoms over a period span- 


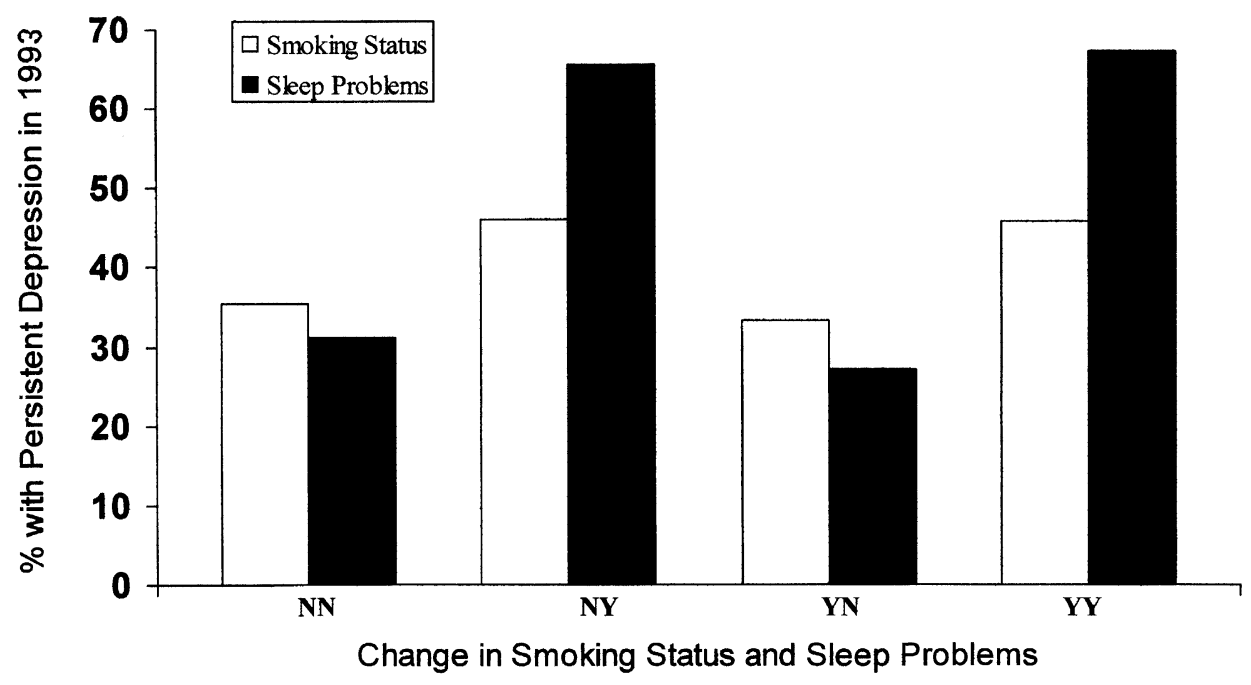

Figure 1. Percentage of adolescents with notable depressive symptoms in 1993 by changes in frequent sleep problems and cigarette smoking status among all 1,176 adolescents with notable depressive symptoms in 1989. YY indicates those adolescents with frequent sleep problems at both years; YN indicates those who reported frequent depressive symptomsat baseline but not at follow-up; NY indicates those without frequent sleep problems at baseline but who reported frequent sleep problems at follow-up; NN indicates those without frequent sleep problems at both years. Similar coding was used for cigarette smoking status.

ning four years. Assuming the majority of depressed adolescents are not receiving treatment, the findings suggest the need for secondary interventions to prevent escalation to more serious problems (e.g., suicidal attempts, MDD, alcohol abuse). In particular, future research is needed to evaluate whether interventions focused on reduction or prevention of sleep problems and cigarette smoking reduce the likelihood of continued depression in adolescents.

\section{ACKNOWLEDGMENTS}

This study was supported in part by the California Tobacco Related Disease Research Program grants 7KT-0091 and 4RT0301; American Cancer Society grant \#RPG-98-263-01-PBP; and the National Institutes of Health grant MH30914 to the UCSD Mental Health Clinical Research Center.

\section{REFERENCES}

Allen KF, Moss AJ, Giovino GA, Shopland DR, Pierce JP (1992): Teenage tobacco-use: Data estimates from the Teenage Attitudes and Practices Survey: United States,
1989. Advance data; no. 224. Hyattsville, MD, National Center for Health Statistics

Choi WS, Patten CA, Gillin JC, Kaplan RM, Pierce JP (1997): Cigarette smoking predicts development of depressive symptoms among US adolescents. Ann Behav Med 19:42-50

Cole DA, Peeke L, Dolezal S, Murray N, Canzoniero A (1999): A longitudinal study of negative affect and selfperceived competence in young adolescents. J Pers Soc Psychol 77:851-862

Frost AK, Reinherz HZ, Pakiz-Camras B, Giaconia RM, Lefkowitz ES (1999): Risk factors for depressive symptoms in late adolescence: A longitudinal community study. Am J Orthopsychiatry 69:370-381

Goodman E, Capitman J (2000): Depressive symptoms and cigarette smoking among teens. Pediatrics 106:748-755

Goodyer IM, Germany E, Gowrusankur J, Altham P (1991): Social influences on the course of anxious and depressive disorders in school-age children. Br J Psychiatry 158:676-684

Kandel DB, Davies M (1982): Epidemiology of depressive mood in adolescents. Arch Gen Psychiatry 39:1205-1212

Patten CA, Choi WS, Gillin JC, Pierce JP (2000): Depressive symptoms and cigarette smoking predict development and persistence of sleep problems in US adolescents. Pediatrics 106:1-9 